\title{
Enhanced Mechanical Properties of Aluminium Alloy EN AW 6082 Recycled without Remelting
}

\author{
Jure KROLO, Branimir LELA, Petar LJUMOVIĆ, Petra BAGAVAC
}

\begin{abstract}
Main aim of this research was to investigate unconventional method for aluminium recycling. Recycling process presented in this research was performed in solid state and therefore is called solid state recycling (SSR) or direct recycling. Main aim of direct recycling approach is to reduce greenhouse gasses emission compared with primary aluminium production and conventional recycling. Other advantages are higher scrap material yield during recycling and energy savings. In this paper, SSR process consisted of aluminium chips hot extrusion and afterwards severe plastic deformation process at room and elevated temperatures. Mechanical properties of the solid state recycled samples obtained by presented process were comparable with samples obtained by conventional manufacturing. Furthermore, it was shown that additional plastic deformation after hot extrusion significantly improved mechanical properties of the recycled samples compared with those recycled only by hot extrusion. Analysis of both microstructure and density analysis was also performed.
\end{abstract}

Keywords: aluminium; ECAP; mechanical properties; microstructure; solid state recycling

\section{INTRODUCTION}

Aluminium recycling is very important in sustainable aluminium industry. More than $30 \%$ of total produced aluminium is from recycling [1]. Energy consumption and greenhouse emissions for aluminium recycling are $95 \%$ lower than for the primary aluminium production [2]-[4]. Aluminium market is in constant increase and predictions are that aluminium production will be increased by more than $42 \%$ in period from 2015 to 2020 [1]. However, greenhouse emissions should remain the same or even get reduced [1], [5]. Therefore, the necessity for new technologies development in the field of aluminium recycling is of the main importance [5]. In the last few years, various authors investigated solid state recycling as novel method to reduce greenhouse emission in the aluminium industry. Utilizing above mentioned process significant energy also material savings can be achieved [6]-[8]. High metal reactivity is responsible for lower material yield in conventional recycling process [8]. Therefore, small size aluminium waste (e.g. machining chips, wires) which has tendency to burn and mix with slag during conventional recycling is usually recycled by SSR process. According to previous investigation $90 \%$ energy savings are possible with SSR compared with conventional recycling [6]-[9]. Furthermore, during conventional remelting greenhouse emissions are $0,3 \mathrm{kgCO}_{2} / \mathrm{kgAl}^{2}[10]$, while for SSR process performed utilizing direct hot extrusion this was calculated to be only $0,01 \mathrm{kgCO}_{2} / \mathrm{kgAl}$ [11]. There are various methods used for SSR and most promising and investigated method is direct hot extrusion [12]. Lately, severe plastic deformation (SPD) processes were also used for SSR because they fulfil some crucial conditions which are necessary to improve recycled samples properties. It has been shown by various authors that the combination of high temperature, increased normal contact stress, shear stress and strain lead to good material bonding and quality recycled samples [6], [13]. Some of the used SPD methods are friction stir extrusion (FSE) [14], high pressure torsion (HPT) [15] and equal channel angular pressing (ECAP) [16]-[18]. In [19] the authors successfully utilized ECAP process for solid state recycling. However, they integrated ECAP die into hot direct extrusion process (so called iECAP) in order to recycle quality aluminium samples from machining chips [19]. In [16] the authors used only ECAP process for aluminium chips recycling. They performed ECAP at $490{ }^{\circ} \mathrm{C}$ with 3 material passes through ECAP die in order to achieve good bonding between chips. However, visible oxide layers and voids between recycled chips suggested that further improvement of the process was necessary. In [18] and [19] the authors successfully recycled titanium alloy machining chips utilizing ECAP process on elevated temperature.

Main aim of this research was to investigate combination of hot extrusion and afterwards ECAP process at room and elevated temperatures as method for solid state recycling. Furthermore, process parameters were varied in order to evaluate different parameters influence on SSR samples quality and mechanical properties. Investigated process parameters were temperature of direct hot extrusion and ECAP process. Furthermore, number of sample passes in ECAP die was investigated. In this research, machining chips from aluminium alloy EN AW 6082 were recycled. In [20] mentioned parameters were investigated for the same alloy in other to determine their influence on micro hardness and electrical conductivity of the recycled samples. However, additional research of the quality of the SSR samples was done in this paper where tensile tests were performed, as well as microstructure and micro porosity analysis with scanning electron microscope. According to the available literature SSR of mentioned aluminium alloy was recycled only in two more papers, however with different SSR processes than presented here [21], [22].

Mechanical properties of the SSR samples obtained with direct hot extrusion and following ECAP were significantly improved in comparison with SSR samples obtained only with direct hot extrusion. Analysis of density of solid state recycled samples was also performed.

\section{EXPERIMENTAL PROCEDURE}

In order to perform SSR, aluminium machining chips were taken from industrial manufacturing process. Chips were collected from turning and milling in different shapes 
and sizes. Fig. 1a shows various sizes of chips obtained after different machining processes. Due to excellent machinability of the selected EN AW 6082 aluminium alloy, machining chips are widely available. Chips collected from manufacturing processes were not from same material batch. Therefore, chemical composition presented in Tab. 1 is given according to commonly used EN-573-3 standard, where each alloying element is defined from minimum to maximum possible value. However, during waste material collection it was necessary to pay attention to avoid mixture of different aluminium alloys or mixture with steel or copper chips. Chips obtained by machining process are usually contaminated with cooling and lubrication oil, so the first step needed to perform solid state recycling was cleaning of the chips. In this research cleaning was performed with ultrasonic bath (ASonic PRO60). For the cleaning purposes universal detergent was used and bath temperature was set at $60^{\circ} \mathrm{C}$. Duration of the cleaning process was 20 minute with $40 \mathrm{kHz}$ ultrasonic frequency. In order to avoid contamination with cooling and lubrication fluid dry machining or cooling with compressed air can be employed. Second phase was cold compaction of the machined chips into billets with $300 \mathrm{kN}$ force, Fig. 1b. Billets diameter and height were $38 \mathrm{~mm}$ and $70 \mathrm{~mm}$, respectively. Compaction was performed on hydraulic press while the force was measured with HBM1MN load cell. Prior to hot extrusion, compacted billets were preheated on selected extrusion temperature in a time of 30 minutes. Hot extrusion temperatures were $400{ }^{\circ} \mathrm{C}, 450{ }^{\circ} \mathrm{C}$ and $500{ }^{\circ} \mathrm{C}$ with 7,1 extrusion ratio. Fig. $1 \mathrm{c}$ shows extruded bar with $15 \mathrm{~mm}$ in diameter. Extruded bars were ECAPed at room $\left(20^{\circ}\right)$ and elevated temperature (160 ${ }^{\circ} \mathrm{C}$ and $\left.300{ }^{\circ} \mathrm{C}\right)$. At room temperature and at $160^{\circ} \mathrm{C}$ one, three and four passes were applied, while at $300{ }^{\circ} \mathrm{C}$ only one pass was applied.

Table 1 Chemical composition of aluminium alloy EN AW 6082

\begin{tabular}{|c|c|c|c|c|c|c|c|c|c|}
\hline Element & $\mathrm{Si}$ & $\mathrm{Fe}$ & $\mathrm{Cu}$ & $\mathrm{Mn}$ & $\mathrm{Mg}$ & $\mathrm{Zn}$ & $\mathrm{Ti}$ & $\mathrm{Cr}$ & Others \\
\hline Min. (\%) & 0,7 & 0 & 0 & 0,1 & 0,6 & 0 & 0 & 0 & 0 \\
\hline Max. (\%) & 1,3 & 0,5 & 0,1 & 0,4 & 1,2 & 0,2 & 0,1 & 0,25 & 0,15 \\
\hline
\end{tabular}

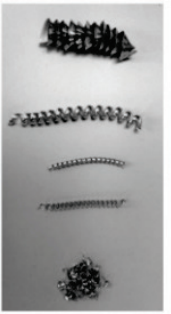

a)

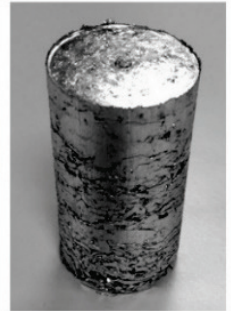

b)

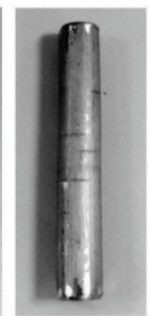

c)

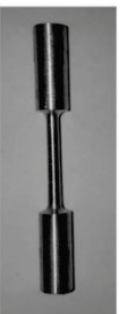

d)
Figure 1 a) aluminium chips, b) compacted billet, c) extruded bar, d) machined recycled sample after ECAP

The main goal of the ECAP process was to refine microstructure. However, in this research ECAP should also assist in aluminium waste bonding improvement because of the process characteristic to introduce significant plastic strain into recycled material. ECAP geometry defined inner die angle and outer die angle [20]. ECAP tool in this work has inner die corner angle value $90^{\circ}$, while outer die corner had $3 \mathrm{~mm}$ radius which forms outer die angle of $12^{\circ}$. The diameter of the ECAP tool channel is $15,1 \mathrm{~mm}$. Fig. 2 shows ECAP tool used in this research.

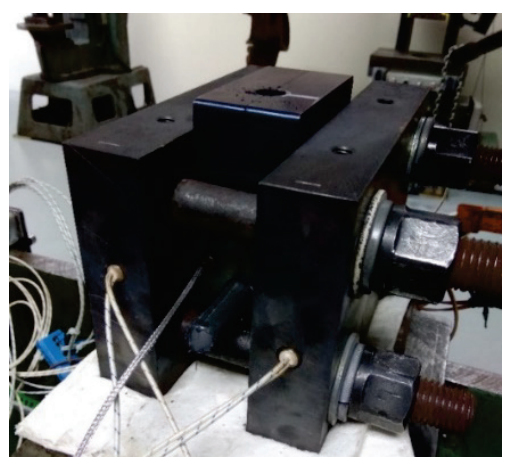

Figure 2 Utilized ECAP tool

The lubrication used at room temperature and $160{ }^{\circ} \mathrm{C}$ was graphite grease, while at $300{ }^{\circ} \mathrm{C}$ lubrication based on $\mathrm{MoS}_{2}$ was utilized. Both temperature measurement and control were performed with Omron E5CC temperature controller. Every sample was preheated for 10 minutes inside ECAP tool. After pass through ECAP samples were heated for another 10 minutes. In order to achieve semicontinuous process samples were pressed one on the other inside ECAP. Mechanical testing was performed according to ASTM E8 standard for metal material tensile testing. The used device was "Instron 8801" $50 \mathrm{kN}$ universal testing machine. Tensile specimens were prepared with gauge original length $10 \mathrm{~mm}$, reduced section length 16 $\mathrm{mm}$ and diameter 2,5 mm, Fig. 1d. Samples were machined from the central part of the recycled samples in order to obtain homogeneous microstructure. Tensile testing was performed at room temperature with the initial strain rate of $1,8 \times 10^{-3} \mathrm{~s}^{-1}$. Optical microscope "OPTON Axioskop" was used for metallography analysis. Samples were brushed, polished and finally etched in duration of $180 \mathrm{~s}$ at $20^{\circ}$. Used reagent was common mixture of $0,5 \mathrm{~mL}$ of $\mathrm{HF}$ (Hydrofluoric Acid) dissolved in $100 \mathrm{~mL}$ of distilled water. More detailed surface metallography analysis was performed with scanning electron microscope (SEM) and energy-dispersive X-ray spectroscopy (EDX). Finally, Mettler Toledo density kit "MS-DNY-43" was used for density measurement.

\section{RESULTS ANALYSIS AND DISCUSSION}

Results after tensile testing for recycled samples are presented in Tab. 2. Furthermore, in Tab. 2 process parameters used for solid state recycling are defined. Fig. 3 shows engineering stress vs. engineering strain diagrams for solid state recycled samples. According to the results for all SSR samples obtained with direct extrusion (DE) and following ECAP process, the ultimate tensile strength (UTS) and yield strength (YS) had increased, compared with SSR samples obtained only with DE (samples 10 and 11). Only sample ECAPed at $300{ }^{\circ} \mathrm{C}$ had lower UTS and YS, however elongation $(\delta)$ was increased.

Furthermore, according to the results ECAP temperature had the most influence on mechanical and physical properties of the recycled samples. Samples ECAPed at $20^{\circ} \mathrm{C}$ had UTS, YS and $\delta$ in range from 249 $\mathrm{MPa}$ to $287 \mathrm{MPa}, 228 \mathrm{MPa}$ to $254 \mathrm{MPa}$ and 5,6 \% to 6,9 $\%$, respectively. Tested mechanical properties were comparable with minimum requirements for conventionally extruded EN AW 6082 in T6 temper condition. Sample 2 ECAPed at $20^{\circ} \mathrm{C}$ had maximal UTS 
and YS and compared with recycled sample obtained only with DE at $450{ }^{\circ} \mathrm{C}$ (sample 11) it had $79,4 \%$ and $159,2 \%$ higher UTS and YS, respectively. However, elongation was $67,4 \%$ lower, Fig. 3. Sample 2 was recycled with 4 ECAP passes at room temperature and as was expected additional strain and grain refinement contributed to UTS and YS increment. In [23] four ECAP passes at room temperature were applied in order to obtain $1 \mu \mathrm{m}$ grain size for same aluminium alloys as used here. Therefore, similar grain refinement was expected in this research. Average UTS, YS and $\delta$ for samples ECAPed at $160{ }^{\circ} \mathrm{C}$ were 196 $\mathrm{MPa}, 163,5 \mathrm{MPa}$ and $12,4 \%$, respectively. These tensile testing values were comparable with minimum requirements for conventionally extruded EN AW 6082 in T4 temper condition. Average UTS, YS for SSR samples ECAPed at $160{ }^{\circ} \mathrm{C}$ compared with sample 11 were $22,5 \%$ and $66,8 \%$ higher, respectively. However, elongation was $27,9 \%$ lower. Sample 9 ECAPed at $300{ }^{\circ} \mathrm{C}$ had enhanced elongation $(21,6 \%)$, however UTS and YS remained low, $140 \mathrm{MPa}$ and $74 \mathrm{MPa}$, respectively (Fig. 3). Solid state recycled sample extruded at $500{ }^{\circ} \mathrm{C}$ and then ECAPed at $160{ }^{\circ} \mathrm{C}$ (sample 8) had enhanced mechanical properties compared with other SSR samples ECAPed at $160{ }^{\circ} \mathrm{C}$, Fig. 3. It was already proven that higher extrusion temperature was desirable in order to obtain quality solid state recycled samples. Higher extrusion temperature had beneficial effect on successful waste bonding. Main reason for that is reduction of the aluminium flow stress with increased temperature, which contributed to the elimination or/and reduction of voids and cracks inside SSR samples [24], [25]. Furthermore, according to the previous studies about billet processing prior extrusion for aluminium $6 \mathrm{xxx}$ series alloys, it was concluded that higher extrusion and preheating temperature $\left(500{ }^{\circ} \mathrm{C}\right)$ probably lead to partial dissolution of $\mathrm{Mg}_{2} \mathrm{Si}$ phase which finally lead to solid solution and therefore precipitation strengthening with a greater extent compared with samples extruded at $400{ }^{\circ} \mathrm{C}$ and $450{ }^{\circ} \mathrm{C}$ [26], [27]. For samples ECAPed at $20{ }^{\circ} \mathrm{C}$ using 3 passes through ECAP die, slightly higher mechanical properties had sample previously extruded at $500{ }^{\circ} \mathrm{C}$ compared with sample extruded at $400{ }^{\circ} \mathrm{C}$, however these differences were small.

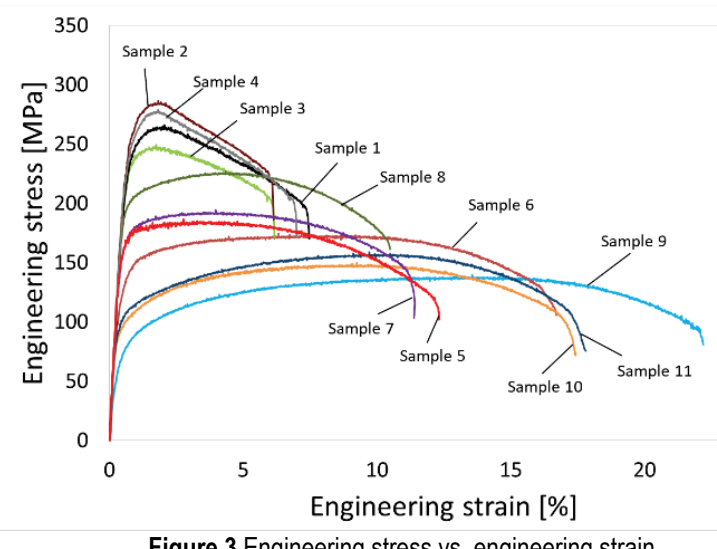

25

Table 2 Process parameters and mechanical properties of solid state recycled samples

\begin{tabular}{|c|c|c|c|c|c|c|}
\hline \multicolumn{7}{|c|}{ Properties of solid state recycled samples obtained utilizing DE+ECAP process } \\
\hline Sample & ECAP temperature $\left({ }^{\circ} \mathrm{C}\right)$ & ECAP pass & DE temperature $\left({ }^{\circ} \mathrm{C}\right)$ & $\operatorname{UTS}(\mathrm{MPa})$ & $Y S(\mathrm{MPa})$ & $\delta(\%)$ \\
\hline 1 & 20 & 3 & 400 & 266 & 240 & 6,9 \\
\hline 2 & 20 & 4 & 450 & 287 & 254 & 5,6 \\
\hline 3 & 20 & 1 & 450 & 249 & 228 & 5,7 \\
\hline 4 & 20 & 3 & 500 & 279 & 248 & 6,4 \\
\hline 5 & 160 & 4 & 400 & 186 & 162 & 12 \\
\hline 6 & 160 & 1 & 400 & 175 & 130 & 16,3 \\
\hline 7 & 160 & 3 & 450 & 194 & 165 & 11 \\
\hline 8 & 160 & 1 & 500 & 227 & 197 & 10,1 \\
\hline 9 & 300 & 1 & 450 & 140 & 74 & 21,6 \\
\hline \multicolumn{7}{|c|}{ Properties of solid state recycled samples obtained utilizing DE process } \\
\hline Sample & DE temperature $\left({ }^{\circ} \mathrm{C}\right)$ & $\operatorname{UTS}(\mathrm{MPa})$ & $Y S(\mathrm{MPa})$ & \multicolumn{3}{|c|}{$\delta(\%)$} \\
\hline 10 & 400 & 150 & 95 & \multicolumn{3}{|c|}{16,9} \\
\hline 11 & 450 & 160 & 98 & \multicolumn{3}{|c|}{17,2} \\
\hline \multicolumn{7}{|c|}{ Conventionally produced EN AW 6082 extruded bar properties } \\
\hline & State & $\operatorname{UTS}(\mathrm{MPa})$ & $Y S(\mathrm{MPa})$ & \multicolumn{3}{|c|}{$\delta(\%)$} \\
\hline & $\mathrm{O}$ & $\leq 160$ & $\leq 110$ & \multicolumn{3}{|c|}{$\geq 14$} \\
\hline & $\mathrm{T} 4$ & $\geq 205$ & $\geq 110$ & \multicolumn{3}{|c|}{$\geq 14$} \\
\hline & T6 & $\geq 295$ & $\geq 250$ & \multicolumn{3}{|c|}{$\geq 8$} \\
\hline
\end{tabular}

\section{MICROSTRUCTURE ANALYSIS}

According to the microstructure analysis all samples had characteristic Al-Mg-Si phases. For used aluminium alloy commonly these phases are characterized as $\mathrm{Al}(\mathrm{FeMn}) \mathrm{Si}$ and (MgSi) phase particles [23], [28]). Furthermore, all recycled samples obtained with combination of direct extrusion and ECAP process had good microstructure without any voids and cracks. This was also confirmed with density measurement where average density measurement for solid state recycled samples ( 1 to 9) was $2698 \mathrm{~kg} / \mathrm{m}^{3}$. This is similar density as in conventional aluminium EN AW 6082 alloy, 2700 $\mathrm{kg} / \mathrm{m}^{3}$. Material density measurement is a good method to determine possible material porosity, however when only some microporosity is present in material metallographic analysis gives much better insight into recycled material quality. Fig. 4 shows samples 3 and 8 with homogeneous microstructure which is characteristic for almost all recycled samples obtained with DE and ECAP.

Furthermore, in some SSR samples oxide layers between chip boundaries could be detected, Figs. 5 and 6 . However, these layers were fractured and they had negligible influence on mechanical properties of solid state recycled samples. Fig. 5b shows cracked oxide layers on chip boundaries. According to the results, sample 4 presented in Fig. 5 had visible chip boundaries, but enhanced mechanical properties, Tab. 2. There was not a 
general rule when chips boundaries will occur in SSR samples during metallographic analysis. Authors considered that main reason for that is randomized mixture of the chips with different shapes and sizes. In this research the real industrial environment was simulated and all kinds of chips were randomly collected from different machining processes. Therefore, in some parts of the samples recycled from smaller chips more chip boundaries occurred than in those recycled with larger aluminium chips.
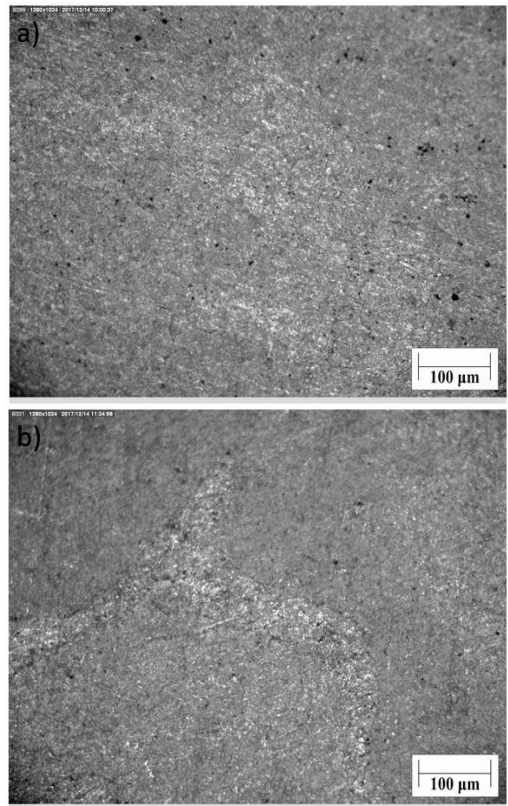

Figure 4 Optical microscope microstructure images of solid state recycled samples with $100 \times$ magnification: a) sample 3, b) sample 8

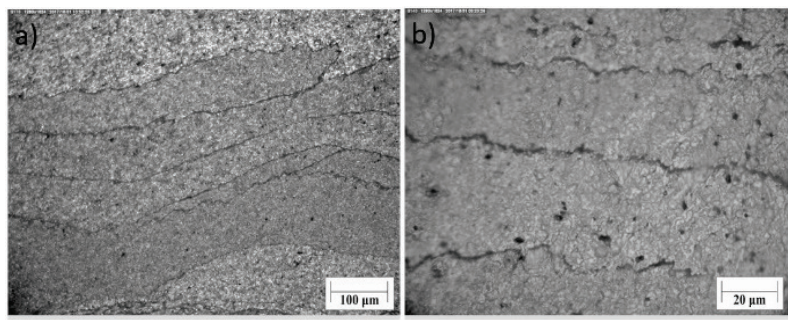

Figure 5 Optical microscope microstructure images of solid state recycled sample 4: a) $100 \times$ magnification of chips boundaries, b) $500 \times$ magnification of fractured chips boundaries

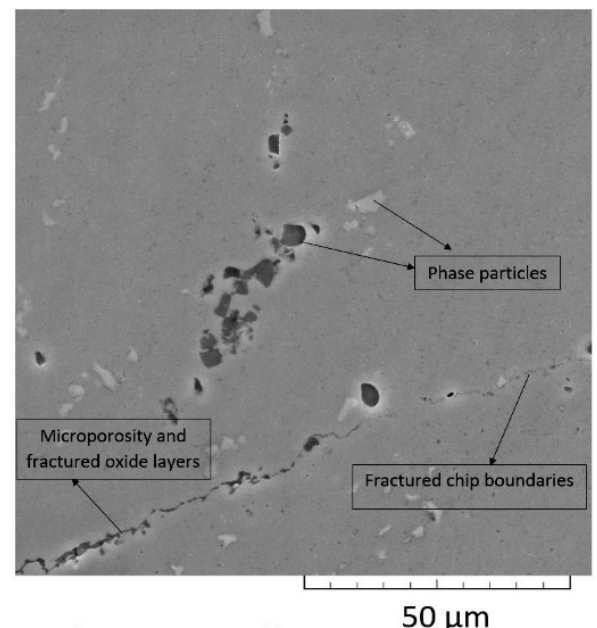

Figure 6 SEM microstructure images of solid state recycled sample 4: 2000x magnification of fractured chips boundaries, microporosity and phase particles
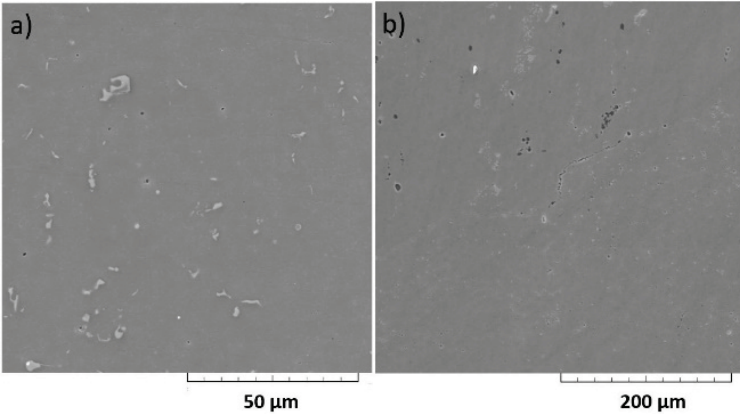

Figure 7 SEM microstructure images: a) the conventionally extruded EN AW 6082 bar in T6 condition b) solid state recycled sample 4
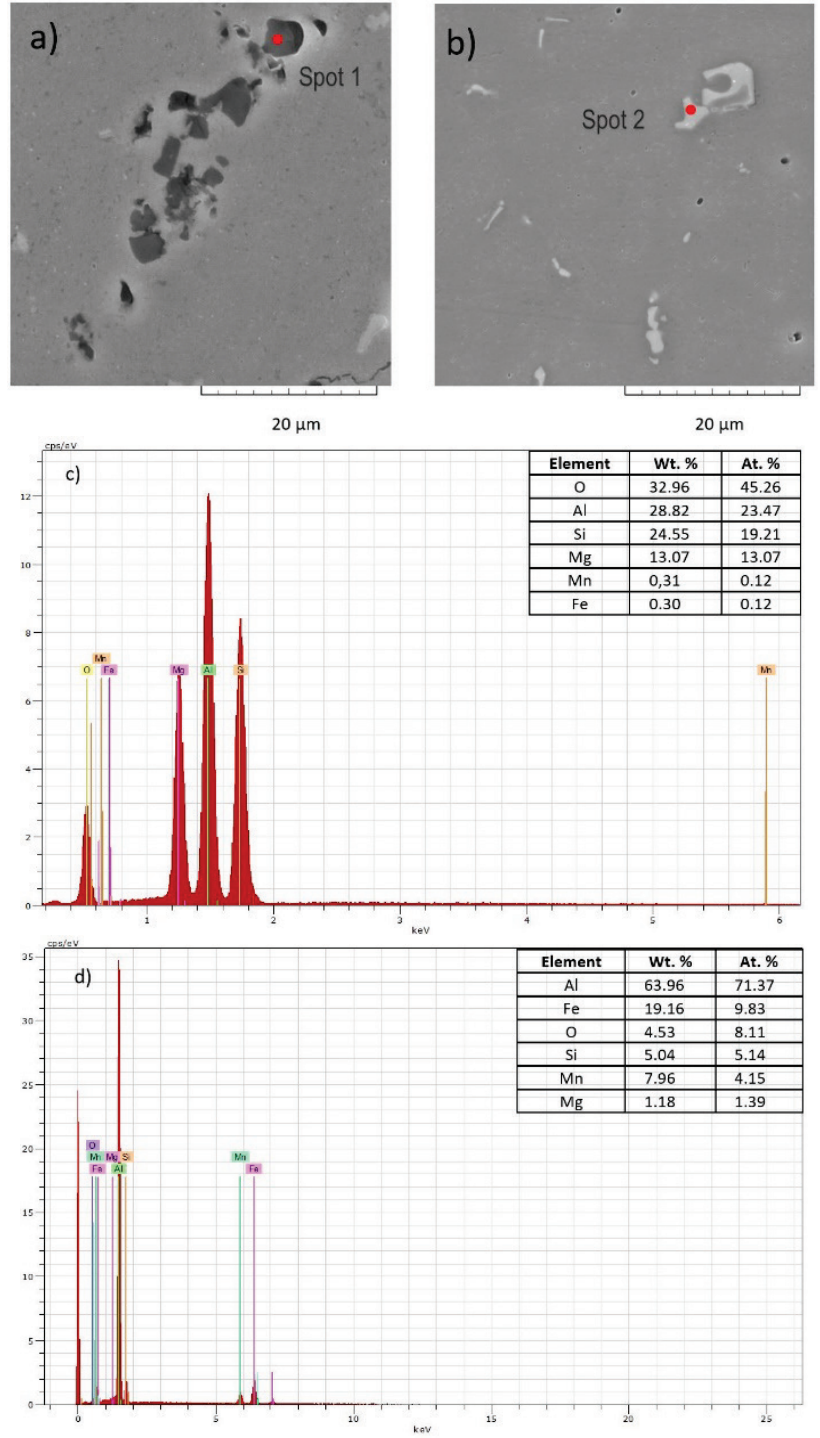

Figure 8 SEM microstructure images and EDX analysis: a) MgSi phase particles on sample 4; b) $\mathrm{Al}(\mathrm{FeMn}) \mathrm{Si}$ phase particles on commercially produced EN AW 6082 T6 extruded bar; c) EDX results for MgSi phase particles; d) EDX results for $\mathrm{Al}(\mathrm{FeMn})$ Si particles

More detailed analysis was performed with scanning electron microscope and energy-dispersive X-ray spectroscopy with technical designation TESCAN VEGA 5136MM. Samples were brushed, polished and finally etched with $0,5 \%$ solution of the HF dissolved in distilled water in time of 8 seconds at room temperature. SEM analysis of the sample 4 showed more heterogeneous microstructure (Figs. 6 and 7 b) compared with the conventionally extruded bar of the EN AW 6082 aluminium alloy in T6 condition (Fig. 7 a). Heterogeneous 
surface of the sample 4 was pronounced because phase particles were distributed randomly inside samples. Main reason for that is significant plastic deformation in cold and hot conditions of aluminium waste without any additional heat treatment. Therefore, heat treatment should assist in more homogeneous phase particles distribution as for conventional sample, Fig 7 a. Furthermore, on the surface of sample 4 both cracked oxide layers on chip boundaries and some microporosity were visible, Figs. 6 and $7 \mathrm{~b}$. However, according to Fig. $7 \mathrm{~b}$, sample 4 does not have any large cracks and voids. Despite the fact that waste material was collected from real industrial environment SEM analysis showed that on observed recycled samples there were not any significant contaminations with impurities. However, it is very important to avoid any mixture between different aluminium alloys, steel or cooper chips, in order to preserve material homogeneity. Furthermore, some impurities such as dust or small pieces of non-metallic particles (i.e. plastic) can behave as weakening points inside material which will lead to lower mechanical properties.

Furthermore, during scanning electron microscopy analysis $\mathrm{Al}(\mathrm{FeMn}) \mathrm{Si}$ and $\mathrm{MgSi}$ phase particles were clearly visible, Figs. 6, 7 and 8. SEM and energy-dispersive $\mathrm{X}$-ray spectroscopy analysis confirmed that dark spots were MgSi phase particles (Figs. 8a and 8c), while the bright spots were $\mathrm{Al}(\mathrm{FeMn}) \mathrm{Si}$ phase particles (Figs. $8 \mathrm{~b}$ and 8d). For conventionally extruded EN AW 6082 bar in T6 condition MgSi phase particles were in a form of the fine precipitates and they cannot be clearly distinguished with used magnification, Fig. 7a. During SEM + EDX analysis in this research any significant contaminations with impurities such as dust or some other metallic materials alloy than aluminium (i.e. steel chips) were not found.

According to the metallographic analysis and tensile testing results it seems that 1 ECAP pass at room temperature is sufficient to produce quality solid state recycled samples, Figs. 3 and 4. However, increase in number of ECAP passes at room temperature increased mechanical properties of the recycled sample. Number of ECAP passes at $160{ }^{\circ} \mathrm{C}$ and $300{ }^{\circ} \mathrm{C}$ had negligible influence on mechanical properties. This research clearly shows that mechanical properties of the solid state samples can easily be manipulated with different SSR process parameters. In [24], [25] and [29] it was concluded that direct hot extrusion process with small extrusion ratio $(\lambda<10)$ was not sufficient to obtain SSR samples without microporosity and cracks. However, this research clearly indicated that hot extrusion with low extrusion ratio $(\lambda=7,1)$ in combination with afterwards ECAP process could be used for successful solid state recycling. Furthermore, even lower extrusion temperatures $\left(400{ }^{\circ} \mathrm{C}\right)$ can be used. Lower extrusion temperatures are desirable because of the lower energy consumption. However, as mentioned before higher temperatures can have beneficial effect on porosity reduction. In this research, visible microporosity inside recycled sample does not have pronounced influence on tensile testing results. However, influence of microporosity can be problematic in case of the material fatigue behaviour and therefore fatigue testing is recommended for some future investigations.

\section{CONCLUSION}

This research showed that quality SSR samples from EN AW 6082 machined chips waste can be obtained with presented SSR process (direct extrusion followed by ECAP). Mechanical properties and density measurements of the recycled samples were comparable with minimum requirements for conventionally extruded EN AW 6082 aluminium alloy. Generally, solid state recycled samples ECAPed at room temperature had mechanical properties comparable with commercially EN AW 6082 extruded bar in T6 condition, while recycled samples ECAPed at $160^{\circ} \mathrm{C}$ had mechanical properties comparable with EN AW 6082 extruded bar in T4 condition. Significant improvement of the mechanical properties compared with samples recycled only with direct extrusion was determined. For solid state recycled sample 2 ultimate tensile strength and yield strength were $79,4 \%$ and $159,2 \%$ higher. Furthermore, higher direct hot extrusion $\left(500{ }^{\circ} \mathrm{C}\right)$ in presented SSR process increased mechanical properties of the recycled samples compared with samples recycled with lower extrusion temperature $\left(400{ }^{\circ} \mathrm{C}\right.$ and $\left.450{ }^{\circ} \mathrm{C}\right)$. However, these differences were small. Furthermore, number of sample passes through ECAP at $160^{\circ} \mathrm{C}$ had negligible influence on mechanical properties. When ECAP was performed at room temperature increase in number of ECAP passes significantly increased mechanical properties of the SSR samples. Furthermore, it was shown that even lower extrusion temperature (e.g. $450{ }^{\circ} \mathrm{C}$ ) and extrusion ratio $(\lambda=7,1)$ could be used for SSR process if the only one ECAP pass was applied afterwards at room temperature or at elevated temperature $\left(160{ }^{\circ} \mathrm{C}\right)$. These conclusions are important due to the energy savings. Furthermore, SSR samples ECAPed at $300{ }^{\circ} \mathrm{C}$ had low mechanical properties and this high ECAP temperature is not necessary. All presented results are without any additional heat treatment, however heat treatment should assist for further mechanical properties improvement. Therefore, use of higher ECAP temperature could assist in microporosity reduction and with additional heat treatment mechanical properties should be increased. Finally, future research should be based on combination of heat treatment and solid state recycling using the presented process. In order to determine negative influence of possible microporosity inside recycled samples fatigue testing is suggested.

\section{Acknowledgements}

This research did not receive any specific grant from funding agencies in the public, commercial, or not-forprofit sectors.

\section{REFERENCES}

[1] International Aluminium Institute (2009). Global Aluminium Recycling: A Cornerstone of Sustainable Development, Retrieved from http://www.worldaluminium.org/media/filer_public/2013/01/15/f10000181.pdf

[2] Stacey, M. (2015).Aluminium Recyclability and Recycling; Towards Sustainable Cities, Nottingham + Llundain, Cwningen Press, Retrieved from http://www.worldaluminium.org/media/filer_public/2016/10/03/tsc_report2 arr_72dpi_release_locked_1016.pdf 
[3] European Aluminum (2016). Moving to a low carbon society, Retrieved from https://www.europeanaluminium.eu/media/1861/activity-report-2016_web.pdf

[4] International Aluminium Institute (2014, November). Environmental Metrics Report v1.1: Year 2010 Data, London, Retrieved from http://www.world-aluminium.org/ media/filer_public/2015/04/16/environmental_metrics_repo rt v11 14th apr.pdf

[5] Allwood, J. M., Cullen, J. M., Cooper, D. R., Milford, R. L., Patel, A. C. H., Carruth, M. A., \& McBrine, M. (2010, September). Conserving our metal energy: Avoiding melting steel and aluminum scrap to save energy and carbon, Retrieved from http://www.uselessgroup.org/files/wellmet 2050-conserving-our-metal-energy-sept-2010-web.pdf

[6] Tekkaya, A. E., Schikorra, M., Becker, D., Biermann, D., Hammer, N., \& Pantke, K. (2009). Hot profile extrusion of AA-6060 aluminum chips. Journal of Materials Processing Technology, 209(7), 3343-3350.

https://doi.org/10.1016/j.jmatprotec.2008.07.047

[7] Gronostajski, J., \&Matsuzak, A. (1999). The recycling of metals by plastic deformation: an example of recycling of aluminum and its alloy chips. Journal of Materials Processing Technology, 92-93, 35-41. https://doi.org/10.1016/S0924-0136(99)00166-1

[8] Duflou, J. R., Tekkaya, A. E., Haase, M., Welo, T., Vameemsel, K., Kellens, K., Dewulf W., \& Paraskevas, D. (2015). Environmental assessment of solid state recycling routes for aluminium alloys: Can solid state processes significantly reduce the environmental impact of aluminium recycling? CIRP Annals- Manufacturing Technology, 64(1), 37-40. https://doi.org/10.1016/j.cirp.2015.04.051

[9] Allwood, J. M., Cullen, J. M., \& Carruth, M. A. (2012). Sustainable Materials with Both Eyes Open, UIT Cambridge.

[10] European Aluminium Association (April, 2008). Environmental Profile Report for the European Aluminium Industry, Life Cycle Inventory data for aluminium production and transformation processes in Europe, Retrieved from http://aluminiumcentrum.nl//files/Doc/ EAA_Environmental_Profile_Report_-_April_2008.pdf

[11] Technical University of Dortmund - TUD. (2010). Retrieved fromhttp://www.lcmp.eng.cam.ac.uk/wp-content/uploads/ W5-Solid-Bonding.pdf.

[12] Shamsudin, S., Lajis, M. A., \& Zhong, Z. W. (2016). Solidstate recycling of light metals: A review, Advances in Mechanical Engineering, 8(8), 1-23. https://doi.org/10.1177/1687814016661921

[13] Cooper, D. R. \& Allwood, J. M. (2014). The influence of deformation conditions in solid-state aluminium welding processes on the resulting weld strength, Journal of Materials Processing Technology, 214(11), 2576-2592. https://doi.org/10.1016/j.jmatprotec.2014.04.018

[14] Tang, W. \& Reynolds, A. P. (2010). Production of wire via friction extrusion of aluminum alloy machining chips, Journal of Materials Processing Technology, 210(15), 22312237. https://doi.org/10.1016/j.jmatprotec.2010.08.010

[15] Mohamed Ibrahim, A. E. A., Eun Yoo, Y., \& Hyoung, S. K., (2013). Recycling of AlSi8Cu3 alloy chips via high pressure torsion, Materials Science \& Engineering A, 560, 121-128. https://doi.org/10.1016/j.msea.2012.09.045

[16] Cui, J., Werenskoild, J. C., \& Roven, H. J. (2009). New approaches for recycling of aluminum scraps, SA, 20-23 September 2009. Warrendale, PA: The Minerals, Metals \& Materials Society (TMS).

[17] Luo, P., McDonald D. T., Zhu, S. M., Palanisamy, S., Dargusch, M. S., \& Xia, K. (2012). Analysis of microstructure and strengthening in pure titanium recycled from machining chips by equal channel angular pressing using electron backscatter diffraction, Materials Science and Engineering A, 538, 252-258. https://doi.org/10.1016/j.msea.2012.01.039

[18] McDdonald, D. T., Lui, E. W., Palanisamy, S., Dargusch, M. S., \& Xia, K. (2014). Achieving Superior Strength and Ductility in Ti-6Al-4V Recycled from Machining Chips by Equal Channel Angular Pressing, Metallurgical and materials transactions A, 45(9), 4089-4102. https://doi.org/10.1007/s11661-014-2323-0

[19] Haase, M., Ben Khalifa, N., Tekkaya, A. E., \& Misiolek, W. Z. (2012). Improving mechanical properties of chip-based aluminum extrudates by integrated extrusion and equal channel angular pressing (iECAP). Materials Science and Engineering A, 539, 194-204. https://doi.org/10.1016/j.msea.2012.01.081

[20] Krolo, J. Lela, B., Švagelj, Z., \& Jozić, S. (2018). Adaptive neuro-fuzzy and regression models for predicting microhardness and electrical conductivity of solid-state recycled EN AW 6082, The International Journal of Advanced Manufacturing Technology. https://doi.org/10.1007/s00170-018-2893-x

[21] Behrens, B. A., Frischkorn, C., \& Bonhage, M. (2014). Reprocessing of AW2007, AW6082 and AW7075 aluminium chips by using sintering and forging operations. Prod Eng Res Devel, 8(4), 443-451. https://doi.org/10.1007/s11740-014-0542-2

[22] Southwire Company and Oak Ridge National Laboratory (March 27, 2012). Direct Solid-State Conversion of Recyclable Metals and Alloys, The Welding InstituteEngland, Retrieved from https://www.osti.gov/scitech/ servlets/purl/1039705

[23] Greger, M., Madaj, M., \& Žaček, D. (2014). Structural and mechanical properties of en aw 6082 aluminum alloy produced by equal-channel angular pressing. Materials and technology, 48(6), 953-958.

[24] Lela, B., Krolo, J., \& Jozić, S. (2016). Mathematical modeling of solid-state recycling of aluminum chips. Int $J$ Adv Manuf Technol, 87(1-4), 1125-1136. https://doi.org/10.1007/s00170-016-8569-5

[25] Shamsudin, S., Zhong, Z. W., Ab Rahim, S. N., \& Lajis, M. A. (2017). The influence of temperature and preheating time in extrudate quality of solid-state recycled aluminum. The International Journal of Advanced Manufacturing Technology, 90(9-12), 2631-2643. https://doi.org/10.1007/s00170-016-9521-4

[26] Birol, Y. (2013). Optimization of homogenization for a low alloyed AlMgSi alloy. Materials Characterizations, 80, 6975. https://doi.org/10.1016/j.matchar.2013.03.013

[27] Steinacher, M., Dragojević, V., \& Smolej, A. (2011). Influence of the heat treatman and extrusion process on the mechanical and microstructural properties of the AlSilMgMn Alloy. RMZ-Materials and Geoenvironment, 58(3), 239-338.

[28] Fujda, M. \& Kvačkaj, T (2007). Microstructure and Mechanical Properties of EN AW 6082 Aluminium Alloy Prepared by Equal-Channel Angular Pressing. Journal of Metals, Materials and Minerals, 17(2), 23-27.

[29] Güley, V., Khalifa, N. B., \& Tekkaya, A. E. (2011). The effect of extrusion ratio and material flow on the mechanical properties of aluminum profiles solid state recycled from 6060 aluminum alloy chips. The $14^{\text {th }}$ International ESAFORM Conference on Material Forming 1, AIP Conference Proceedings, 1353, 1609-1614. https://doi.org/10.1063/1.3589746 


\section{Contact information:}

Jure KROLO, M. Eng., Teaching/Research Assistant

(Corresponding author)

Faculty of Electrical Engineering,

Mechanical Engineering and Naval Architecture,

Ruđera Boškovića 32, 21000 Split, Croatia

jkrolo@fesb.h

Branimir LELA, Dr. Sc., Associate Professor

Faculty of Electrical Engineering,

Mechanical Engineering and Naval Architecture

Ruđera Boškovića 32, 21000 Split, Croatia

blela@fesb.hr

Petar LJUMOVIĆ, Mech. Eng. Spec., Senior Laboratory Technician/Lecturer

Faculty of Electrical Engineering,

Mechanical Engineering and Naval Architecture,

Ruđera Boškovića 32, 21000 Split, Croatia

petarlj@fesb.hr

Petra BAGAVAC4, M. Eng., Teaching/Research Assistant

Faculty of Electrical Engineering,

Mechanical Engineering and Naval Architecture,

Ruđera Boškovića 32, 21000 Split, Croatia

petra.bagavac@fesb.hr 